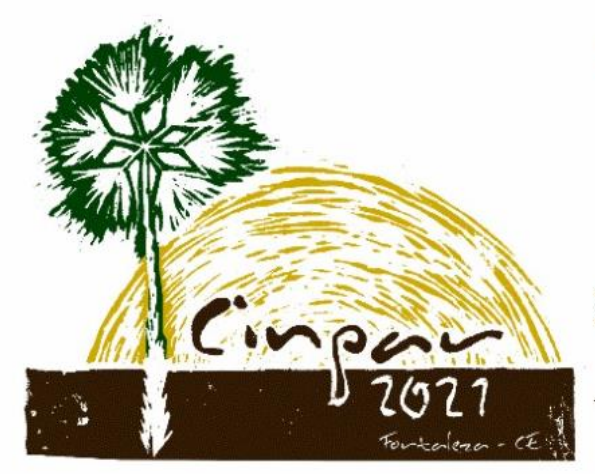

XVII Congresso Internacional sobre Patologia e Reabilitação das Construções

XVII Congreso Internacional sobre Patología y Rehabilitación de las Construcciones

XVII International Conference on Pathology and Constructions Rehabilitation

FORTALEZA (Brasil), 3 a 5 de junho de 2021 https://doi.org/10.4322/CINPAR.2021.102

\title{
Estrategias Técnicas y de Gestión Innovadoras para la Recuperación del Patrimonio Edilicio. El Caso del Oratorio del Cementerio Municipal de Santa Fe (Argentina)
}

\section{Innovative Technical and Management Strategies for the Recovery of Building Heritage. The Case of the Oratory at Santa Fe Municipal Cemetery (Argentina)}

\author{
Manuel Alfredo MINA ${ }^{1}$
}

\author{
${ }^{1}$ Universidad Católica de Santa Fe, Echagüe 7151 CP S3004JBS Santa Fe, Argentina, manuelmina@ucsf.edu.ar
}

Resumen: La conservación del patrimonio construido ha implicado desde siempre el desafío de afrontar herramientas de gestión y estrategias técnicas eficaces a los fines de hacer posibles las acciones necesarias para su concreción.

En los últimos tiempos, la realidad económica de Latinoamérica, el rol zigzagueante del estado frente a su deber en la conservación, combinados con cierta pérdida o menoscabo del conocimiento, teórico y empírico, de las técnicas tradicionales de construcción y reparación, han resultado obstáculos, difíciles de sortear, en la gestión y preservación del patrimonio.

La presencia de los obstáculos mencionados en la gestión del patrimonio, ha tenido como correlato, por un lado, la postergación de acciones imprescindibles para la conservación de muchos referentes edilicios del pasado con el consecuente deterioro por abandono de los mismos y por otro lado, la concreción de algunas intervenciones basadas en modelos técnicos y de gestión, más propias de obras nuevas, que ignoran particularidades esenciales del valor patrimonial y sus desafíos.

A partir de una experiencia eficaz en la puesta en valor del Oratorio del Cementerio Municipal de Santa Fe (Argentina), este trabajo destaca algunos lineamientos de intervención innovadores, tanto en el campo de la gestión como de las acciones técnicas, a fin de dejar testimonio de las mismas y presentarse como variantes útiles a la disciplina.

Palabras clave: patrimonio, conservación, estrategias, gestión, patología

Abstract: The conservation of building heritage has always involved the challenge of facing effective management tools and technical strategies in order to make possible the necessary actions for its realization.

In recent times, the economic reality of Latin America, the zigzagging role of the state in the face of its duty in conservation, combined with a certain loss or decrease of theoretical and empirical knowledge, of traditional construction and repair techniques, have resulted in obstacles, difficult to avoid, in the management and preservation of heritage.

The existence of the mentioned obstacles in heritage management has had different consequences. On the one hand, the postponement of essential actions for the conservation of many building references of the past with the resulting deterioration due to their abandonment; and on the other hand, the implementation of some interventions based on technical and management models, more typical of new construction works, which ignore essential particularities of heritage value and its challenges.

Based on an effective experience in the enhancement of the Oratory at Santa Fe Municipal Cemetery (Argentina), this work highlights some innovative intervention guidelines, both in the field of management and technical actions, in order to leave testimony of them and being offered as useful variants to the discipline.

Keywords: heritage, conservation, strategies, management, pathologies 


\section{Consideraciones Preliminares}

Por un lado, es verdad que asistimos a un proceso, ciertamente virtuoso, de incremento en la conciencia colectiva de la valoración del patrimonio cultural, proceso que exhibe tiempos y profundidades disímiles en distintos países y continentes, pero que reconoce cierta universalidad. Al mismo tiempo, también es cierta la obligación que tenemos, quienes nos vemos ligados a los procesos de gestión y concreción de acciones sobre el patrimonio, de mantener una reflexión constante que, por un lado mantenga viva las explicaciones más profundas -más trascendentes- de por qué es preciso conservar, como así también cuáles son los riesgos de una subvaloración de los bienes culturales o una reducción de su apreciación a términos opinables que podrían, incluso, poner en peligro su permanencia o su integridad.

\section{Revisando la idea de la preservación; ¿Por qué conservar el patrimonio edilicio?}

La pregunta que precede, podría encontrar diversas respuestas - no siempre congruentes- en virtud de la complejidad del fenómeno en cuestión y de las distintas aristas desde las cuales puede ser abordado el interrogante a cerca del por qué de la conservación.

Lejos de desalentar, la complejidad del fenómeno debe animarnos a sumar miradas que fortalezcan una explicación capaz de sostener con mayor eficacia nuestro patrimonio cultural siempre jaqueado por la misma dialéctica, aunque esta reciba distintos apodos: conservación-sustitución; permanencia-cambio; pasadofuturo. Quizás las primeras líneas de una explicación coherente al fenómeno, no deban olvidar que, tal como lo expresa la Socióloga Valcárcel Leyva, esta especie de contradicción o tensión es inherente a los procesos culturales de los pueblos en tanto y en cuanto el patrimonio como concreción creativa tiende a una estabilidad que habitualmente se ve cuestionada por la dinámica de la identidad cultural, más permeable a influencias de diversa naturaleza que la hacen tendiente al cambio. (Valcárcel Leyva, 2011)

Integrar, sin negar, las realidades de permanencia y cambio debiera ser el camino para delinear explicaciones sustentables -en todo el alcance de la palabra- a la consabida pregunta de por qué conservar en un contextocultural contemporáneo, que muchas veces más bien invita a descartar.

Desde un punto de vista sociológico, particularmente desde una hermenéutica cultural, Valcárcel Leyva subraya la existencia de valores presentes y actuantes al momento creativo que explican desde una triple dimensión - ontológica, gnoseológica y axiológica - las características de la sociedad que dio origen al bien patrimonial y por tanto permiten a la misma reconocer rasgos indelebles de su identidad. (Valcárcel Leyva, 2011)

Recientemente, el Papa Francisco, en el contexto de una mirada sobre la ecología integral preocupada por la conservación del planeta - la Casa Común- instala la perspectiva de la "Ecología Cultural" y visualiza un patrimonio histórico igualmente amenazado que el patrimonio natural. Las explicaciones a la amenaza rondan en la interpretación de un contexto social que no resuelve satisfactoriamente aquel mencionado dualismo entre permanencia y cambio, advirtiendo sobre el riesgo de la supresión de rasgos culturales (o aún de culturas completas) de la mano de la imposición de un modelo hegemónico generalmente enraizado en intereses económicos. (Francisco, 2013)

Por último, instalando una mirada, curiosamente relegada en algunos ambientes académicos, el patrimonio cultural tiene una innegable - e imprescindible- dimensión económica la cual no puede ser ignorada porque está estrechamente vinculada a sus posibilidades de permanencia y conservación. Esta realidad económica podría asimilarse a dos vectores: por un lado, los recursos que el patrimonio demanda en virtud de la necesidad de acciones de conservación permanentes, costosas pero eficaces; y por otro lado los recursos que el patrimonio genera a partir de su, no siempre bien resuelta, relación con la actividad turística. Sin duda esta interacción patrimonio cultural - turismo ha adquirido en las últimas décadas, dimensiones inusitadas que la posicionan en el análisis con todo su potencial, pero a la vez con todos sus riesgos (Velasco González, 2019). Finalmente, no es factible abordar la dimensión económica sin tener en cuenta el mundo de los intereses económicos, de la propiedad, del afán de lucro y de todo aspecto que guarde relación con esta dimensión, casi omnipotente, que desde siempre orientó los rumbos de muchas políticas de estado y que hoy pareciera gobernarlo todo desde una inequidad que asusta. 


\section{3 . El panorama actual: Certezas vs. Desconcierto}

\subsection{La valoración de los bienes}

Aceptados los fundamentos del por qué conservar los bienes patrimoniales de una sociedad, aparece un primer desafío, de naturaleza operativa, que será definir ciertas pautas objetivas de valoración del patrimonio que actúen como un horizonte a la hora de decidir qué conservar, cuánto conservar y cómo conservar. Estas pautas han de buscar un pretendido justo medio que evite los extremos de una valoración excesiva que lo patrimonialice todo y de una subvaloración de los bienes que justifique una sustitución despiadada.

A los fines de partir de una definición general capaz de enmarcar cualquier cuerpo de pautas valorativas del patrimonio, conviene recordar la programática definición de la 170 Convención sobre la protección del patrimonio mundial, cultural y natural de la UNESCO: "A los efectos de la presente Convención se considerará "patrimonio cultural": a) los monumentos: obras arquitectónicas, de escultura o de pintura monumentales, elementos o estructuras de carácter arqueológico, inscripciones, cavernas y grupos de elementos, que tengan un valor universal excepcional desde el punto de vista de la historia, del arte o de la ciencia; b) los conjuntos: grupos de construcciones, aisladas o reunidas, cuya arquitectura, unidad e integración en el paisaje les dé un valor universal excepcional desde el punto de vista de la historia, del arte o de la ciencia; c) los lugares: obras del hombre u obras conjuntas del hombre y la naturaleza así como las zonas, incluidos los lugares arqueológicos que tengan un valor universal excepcional desde el punto de vista histórico, estético, etnológico o antropológico." (UNESCO, 1972)

Numerosos trabajos científicos han desarrollado métodos o criterios que ayuden a una valoración objetiva del patrimonio atendiendo tanto a sus diferentes realidades, tanto tangible o intangible, como así también a los valores que el bien en cuestión pueda contener. Para Mayordomo Maya y Hermosilla Pla se deberán evaluar los valores intrínsecos de un bien según las pautas de representatividad, autenticidad e integridad; los valores patrimoniales en sí atendiendo a criterios históricos, sociales, simbólicos, artísticos, técnicos, territoriales, paisajísticos y divulgativos y por último los valores potenciales o de viabilidad en función de niveles de concientización, participación, rentabilidad socioeconómica y vulnerabilidad. (Mayordomo Maya \&Hermosilla Pla, 2020)

Sin pretender agotar la cuestión ciertamente difícil de las pautas de evaluación de los bienes culturales, es importante remarcar la imperiosa necesidad de adoptar un conjunto de pautas, medianamente sistemático, que aporte método científico a una tarea que por años se omitió o bien se basó en erráticos criterios personales.

\subsection{Patrimonio de dominio público o privado}

La citada 170 Convención de la UNESCO asigna a los estados la "obligación la obligación de identificar, proteger, conservar, rehabilitar y transmitir a las generaciones futuras el patrimonio cultural y natural situado en su territorio" (UNESCO, 1972). En esta afirmación, el término obligación, asignado al estado, adquiere un carácter de mandato impostergable e ineludible propio de la importancia de los bienes en cuestión y de la natural responsabilidad de aquel de velar por los intereses comunes.

Aceptada la responsabilidad del estado en la tarea de la conservación, aparece un primer desafío, cuyas connotaciones legales le otorgan gran dificultad, consistente en la propiedad del bien, sea esta pública o privada y en este último caso sea de personas, instituciones o empresas. Valga como ejemplo de esta particular connotación el patrimonio eclesiástico, regulado por un lado por normas canónicas y su relación con la normativa civil (Aparicio Novoa, 2017). Así como existe la propiedad pública- o común- de algunos bienes y existe la propiedad privada, existen el interés colectivo y el interés individual asistido, cada uno de ellos, por razones, fundamentos y connotaciones que usualmente no entran, o no debieran entrar, en contradicción.

La propiedad, más allá de los intereses que la impulsan y sostienen, genera derechos y obligaciones que el marco legislativo de una comunidad regula buscando un equilibrio que garantice la convivencia sin lesionar ambas esferas de interés; ahora bien, cuando aparece en el horizonte del análisis el valor y el interés patrimonial la cuestión adquiere connotaciones ciertamente más complejas. 
Partiendo de la premisa que un bien que forma parte del acervo cultural significativo de una comunidad, interesa al colectivo social por los valores identitarios que atesora y por varias cuestiones ya descriptas, y si el bien aludido es propiedad pública, pareciera que el debate se resuelve con cierta facilidad: el estado que vela por los intereses comunitarios, ejerciendo la obligación de la cual habla la citada convención de UNESCO, preservará y sostendrá con recursos públicos algo que es de neto interés público. Evidentemente la cuestión se vuelve más compleja cuando la propiedad de un bien de interés patrimonial es de dominio privado y como ya se expresó, su conservación en el tiempo, mantenimiento y eventual recuperación son de interés comunitario. Ante este escenario los derechos y obligaciones parecen entrar en un terreno de tensión que predispone al conflicto sin que las normas existentes lo resuelvan siempre de manera eficaz.

\subsection{Las ambigüedades normativas y el rol zigzagueante del Estado}

El Derecho en cuanto sistema de normas que regula la vida social y acompaña su evolución desde la ciencia de la conducta, deberá ayudar a la ciudad y sus habitantes preservando los derechos y custodiando el respeto de cada uno como verdadera expresión de la búsqueda de un equilibrio entre los intereses. (Rondina \& Rondina, 2019) Este concepto fundamental en la organización jurídica de los pueblos debe enfrentar las dificultades del contrapunto de intereses que suele presentarse, es por esto que no basta con la sola existencia de un cuerpo normativo, sino que se vuelve imprescindible la tarea social de concientización, único camino que garantiza su cumplimiento (Querol, 2010).

El Artículo 41 de la Constitución Nacional Argentina declara que. "Las autoridades proveerán a la protección de este derecho, a la utilización racional de los recursos naturales, a la preservación del patrimonio natural y cultural y de la diversidad biológica, y a la información y educación ambientales. Corresponde a la Nación dictar las normas que contengan los presupuestos mínimos de protección, y a las provincias, las necesarias para complementarlas, sin que aquéllas alteren las jurisdicciones locales". (Constitución Nacional Argentina, 1994). Las variantes normativas locales en los distintos niveles del estado y en las distintas jurisdicciones de Argentina, si bien muestran cierta heterogeneidad en sus alcances no han logrado superar en las leyes de preservación de bienes patrimoniales, códigos urbanos y reglamentos de edificación con ciertas restricciones y declaraciones de protección que no suelen satisfacer la total dimensión de la cuestión. Este marco normativo es visto por el común de los ciudadanos, en particular por los intereses de los desarrolladores privados de emprendimientos urbanos, como una normativa solo restrictiva que suele generar conflictos. Si a las limitaciones de eficacia del cuerpo normativo del estado, se le suman los constantes giros ideológicos que los gobiernos en Latinoamérica han enfrentado hace muchas décadas y una constante carencia de medios, fruto de un endémico déficit en las economías de la región, el resultado está a la vista. La suerte que ha corrido el patrimonio cultural de nuestras ciudades ha sido incierta, favoreciendo muchas veces una sustitución despiadada. Numerosos ejemplos del menoscabo del patrimonio edilicio exhiben nuestras ciudades, solo a modo de ejemplo cabe recordar la emblemática casa Tons, construida en 1.890 en la ciudad de Santa Fe (Argentina) en un área urbana que, en los albores del siglo $X X$, se expandía de la mano del desarrollo portuario de la ciudad. Un ejemplar del patrimonio modesto consistente en un gran salón comercial en la planta baja y una vivienda familiar en los altos, con avanzadas resoluciones tecnológicas para la época y finos detalles estilísticos, soportó por años intervenciones distorsionantes, mutilaciones, abandono y finalmente, pese a ser un bien protegido por la normativa municipal de conservación, asistimos a su repentina demolición para ser sustituida por un anodino local comercial.

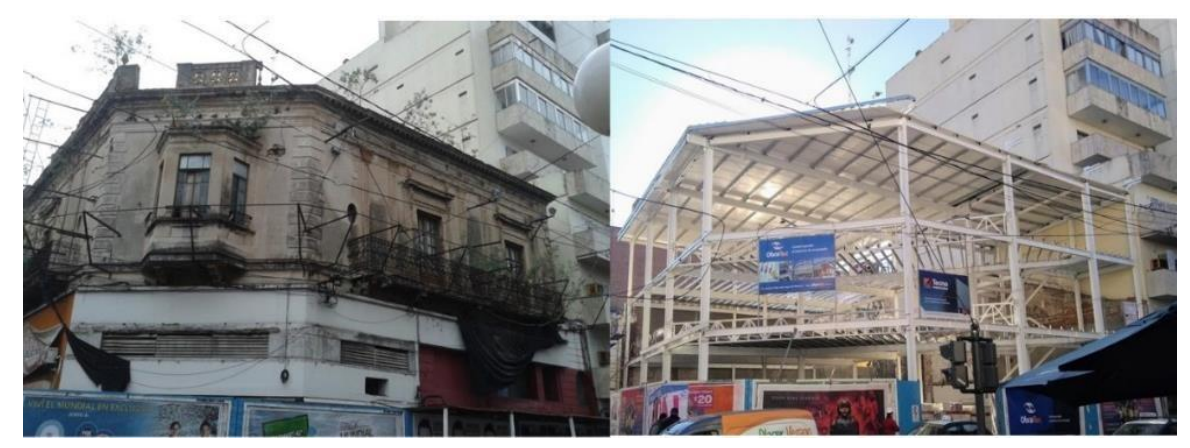

Figura 1 - La Casa Tons en 2015 y su posterior sustitución

Estrategias Técnicas y de Gestión Innovadoras para la Recuperación del Patrimonio Edilicio. 


\subsection{Modelos de gestión y conservación}

Expuesto el panorama complejo de la conservación de referentes edilicios del pasado desde el punto de vista normativo, la realidad actual, al menos en buena parte de la Argentina, muestra que en la esfera privada los edificios suelen ser alcanzados por una ordenanza de protección que en términos prácticos implica una prohibición de demolición o intervención sin antes elevar un expediente a una comisión municipal de patrimonio quien dictaminará a cerca de la necesidad de conservar el bien y autorizará cualquier intervención que el propietario proponga en tanto y en cuanto no afecten los valores patrimoniales que la comisión detecta y pretende conservar (Ordenanza 10.115/96). Hasta allí se limita el rol del Estado y todo esfuerzo económico de conservación o merma en el valor inmobiliario a causa de la restricción, serán soportados por el propietario sin subsidio alguno por parte del Estado. Esta metodología, que en un primer análisis puede ser ponderada por intentar poner freno a la sustitución feroz de la cual fueron víctimas nuestras ciudades, debe ser fuertemente revisada porque impone al privado una carga de interés público sin atender con algún tipo de apoyo que comparta el peso de la restricción y evite una especie de mal humor que la misma suele generar. Cuando el bien es privado, pero pertenece a alguna institución no gubernamental, puede recibir una declaratorio de interés patrimonial - municipal o provincial - que puede contribuir a la asignación de fondos públicos destinados a la conservación, aunque esto no estrictamente exigible por parte del propietario.

En el caso de edificios públicos o pertenecientes a instituciones, que exhiban gran importancia desde el punto de vista patrimonial, los mismos pueden ser declarados Monumentos Históricos Nacionales, declaratoria que los hace participar de los alcances de la Ley 12.665 del año 1.940, su modificación parcial en la Ley 27.103 de 2015 y los correspondientes decretos reglamentarios. Este cuerpo normativo regula la creación y funcionamiento de la Comisión Nacional de Monumentos, Lugares y Bienes Históricos con la función de detectar, proteger y promover a la conservación de los bienes culturales mientras que la histórica Dirección General de Arquitectura (DGA), luego Dirección Nacional de Arquitectura (DNA) y recientemente Dirección Nacional de Planificación y Diseño de Obra Pública (DNPYDOP), será la encargada de proyectar, licitar y supervisar la ejecución de las obras de restauración y conservación. Este cambio de denominación de la repartición estatal parece acompañar una paulatina merma en la importancia y eficacia de la misma en relación a la gestión del patrimonio, condicionada seguramente por las políticas de reducción del Estado y la endémica falta de fondos públicos destinados a sus fines.

Aún en los tiempos de mayor abundancia en obras públicas de puesta en valor de edificios patrimoniales, la metodología de contratación y ejecución de este tipo de obras no escapaba a las generalidades de la ley de Obras Públicas (13.164 de 1.947 y decretos reglamentarios) solo con algunas particularidades relacionadas a la naturaleza del bien, que no siempre alcanzaban a satisfacer la compleja realidad de una obra de conservación. La contratación mediante licitaciones públicas, con precio cerrado, a empresas constructoras sin probados antecedentes en la materia y la inexistencia de proyectos acabados de restauración propiciaron cierto maltrato a los referentes edilicios que definitivamente requieren una metodología de intervención particularmente ajustada a su condición.

\section{La Recuperación del Oratorio del Cementerio Municipal de Santa Fe (Argentina)}

El complejo panorama descripto pretende cumplir la finalidad de continuar alertando sobre la importancia de la conservación del patrimonio edilicio del pasado y de los desafíos que la disciplina debe enfrentar para incrementar su eficacia obteniendo resultados cada vez más alentadores. En el caso que a continuación se presenta, se destacan algunas notas salientes que pueden ser útiles a la hora de intervenir en obras patrimoniales.

\subsection{El Edificio}

El Cementerio Municipal de la Vera Cruz de la ciudad de Santa Fe, Argentina, fue inaugurado en 1.892 de la mano de las normas del higienismo imperante en la época y de la consabida separación de roles entre el estado y la Iglesia Católica quien había monopolizado la cuestión funeraria desde siempre.

Como parte del conjunto edilicio fundacional, junto al pórtico de entrada, se construyó en 1.905, en el cruce de los ejes circulatorios principales del conjunto, un bellísimo templete circular, de marcado acento

Estrategias Técnicas y de Gestión Innovadoras para la Recuperación del Patrimonio Edilicio. 
neorrenacentista, con ineludibles referencias a San Pietro in Montorio de Bramante construido en Roma en 1510. La ubicación del oratorio como punto focal, su edad, su valor simbólico y estético y su sólida e ingeniosa técnica constructiva híbrida de perfiles metálicos y mampostería de ladrillos, le confieren un innegable interés patrimonial largamente menoscabado, al punto de su clausura y vallado por muchos años. Semejante condición de abandono y desuso, más allá de agravar los procesos patológicos presentes y magnificar las acciones de recuperación necesarias, fue llevándolo al menosprecio del común de los asistentes al cementerio indiferentes ante su presencia, ineludiblemente céntrica.

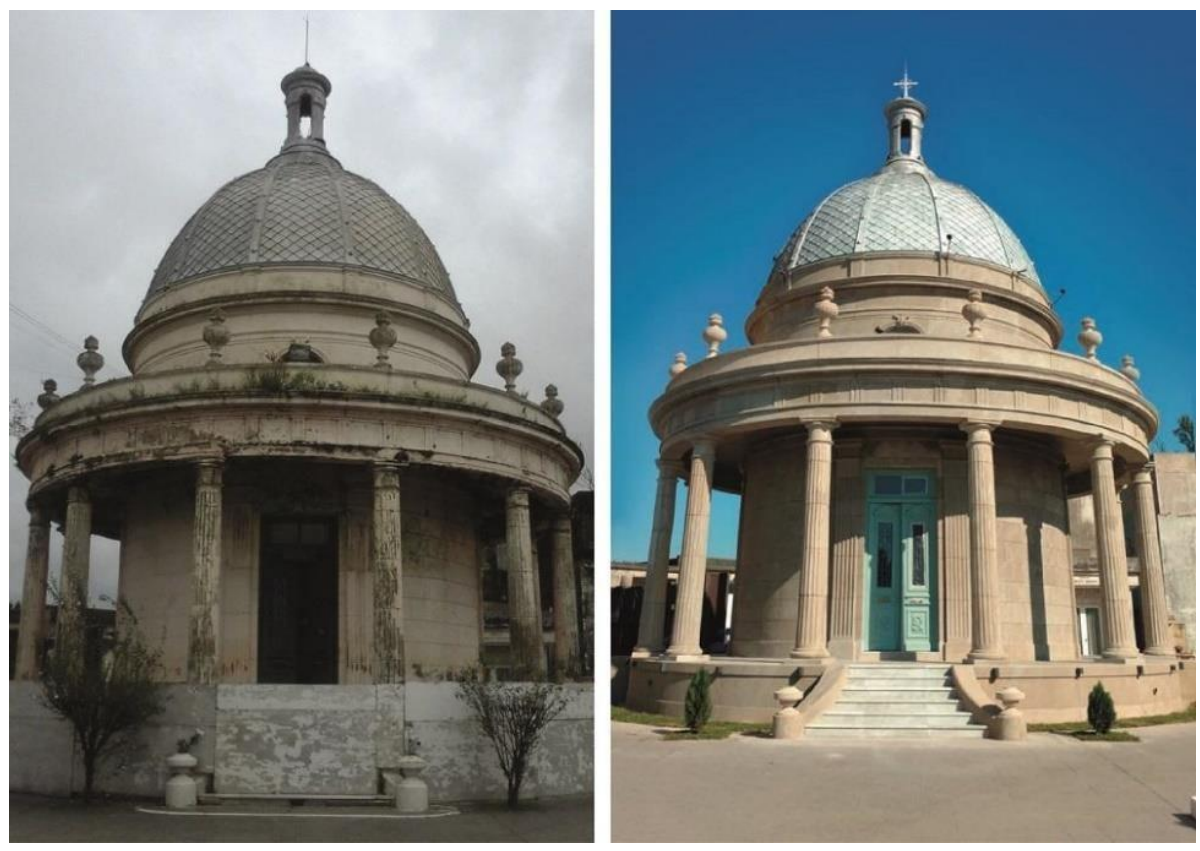

Figura 2 - El Oratorio antes y después de su recuperación

\subsection{El modelo de Gestión}

A partir de la decisión de las autoridades municipales de recuperar el Oratorio, el proceso da inicio con la contratación de equipos profesionales de experiencia en la disciplina y la disposición de los medios necesarios para realizar una profunda evaluación del edificio y todos sus sistemas componentes a fin de establecer pautas de intervención adecuadas. Este proceso fue más allá de un simple relevamiento ya que implicó la realización de cateos, inspecciones en altura, ensayos y demás acciones de evaluación y diagnóstico. El resultado de la tarea de proyecto, se complementó con la elección de un sistema de ejecución de obra por administración, en el cual el Estado conservaba el dominio de las contrataciones secundado por un profesional especializado en restauración, todo esto con el fin de evitar las subcontrataciones masivas por parte de empresas constructoras habituales en la obra pública y buscando idóneos en cada rubro por el mejor precio. Otra nota saliente fue la incorporación del personal habitual de maestranza y de jóvenes participantes de proyectos de formación laboral con interés social, lo que demandó una ardua tarea de capacitación en las técnicas específicas, pero redundó en el enorme beneficio de contar con un staff propio, capacitado en la técnica y disponible tanto para mantener como para encarar nuevas acciones de reparación en otros sectores de interés patrimonial del cementerio. Esta metodología poco frecuente de vinculación de la mano de obra se convirtió en una de las claves para ahorrar recursos y dotar al Estado de operarios entrenados en técnicas cuyo conocimiento tiende a perderse en el mercado de la oferta laboral. Por último, para aquellos rubros o provisiones que requerían la participación de proveedores específicos, se realizaron compulsas de precios entre empresas afines al rubro buscando reducir la cadena de contrataciones y seleccionar con racionalidad. En síntesis, esta experiencia marca que la obra ejecutada por administración de gremios específicos bajo una coordinación común se presenta más favorable que la realización de la misma bajo el sistema de monto global y contrato único. 


\subsection{Variantes técnicas ad-hoc}

El avanzado estado de deterioro de algunos componentes constructivos, las limitaciones en los medios económicos y la disponibilidad de recurrir a especialistas altamente calificados, obligó a planear múltiples estrategias que, sin menoscabar el valor del bien, hicieran viables las intervenciones necesarias con medios accesibles. A modo de ejemplo se cita el caso de las columnas perimetrales que, en virtud de la expansión de los perfiles de hierro de su interior - fruto de un proceso importante de corrosión- presentaban múltiples cuadros de fisuración y desprendimientos de su recubrimiento de mampostería y revoque. La necesidad de descubrir los perfiles a fin de evaluar su estado, recuperarlos o reforzarlos, protegerlos y recubrirlos nuevamente y sin disponer de mano de obra capaz de concretarlo con la técnica tradicional, se optó por tomar moldes del recubrimiento para replicarlos con elementos cementicios premoldeados obteniéndose un resultado correcto en un tiempo razonable y a costos accesibles.
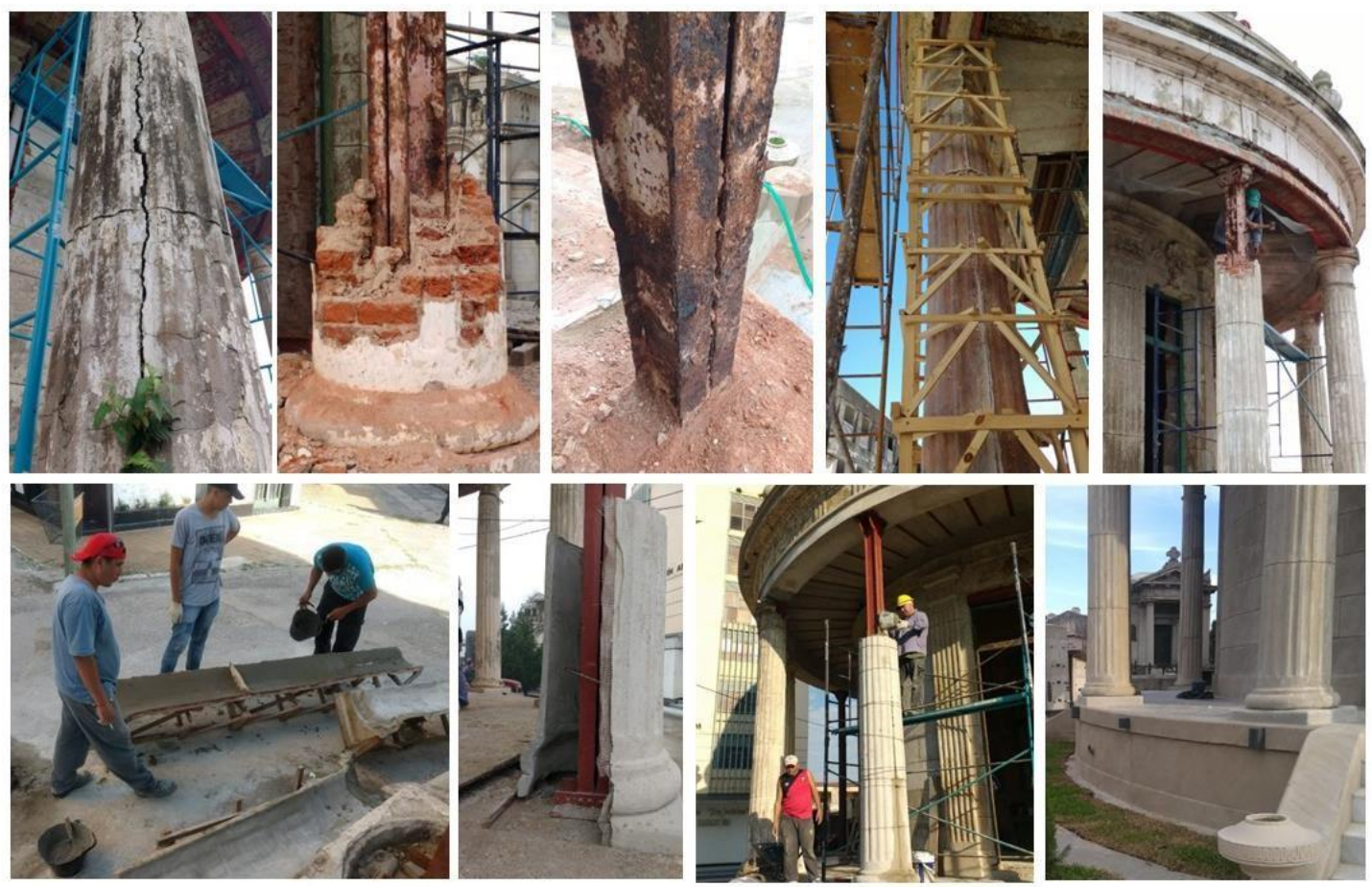

Figura 3 - Secuencia de restauración de columnas

Las acciones para detener la corrosión de perfiles embutidos en toda la estructura, la impermeabilización de cubiertas, la recuperación de la cúpula de zinc y su linterna, la intervención en los paramentos exteriores con una veladura de mortero símil piedra formulado en obra, la restauración de aberturas, marmolería, pintura mural interior y pisos, fueron las acciones principales desarrolladas bajo el mencionado sistema de administración, bajo la conducción del especialista, entrenando mano de obra propia del ente estatal y contratando rubros específicos en aquellos casos imprescindibles.

\subsection{Difusión y reapropiación del patrimonio público}

La ejecución de los trabajos de recuperación del oratorio, dada su ubicación en el conjunto del cementerio, comenzó a despertar el interés de los asistentes que, a lo largo de los 18 meses de obra, observaban las tareas, consultaban detalles y manifestaban sorpresa al descubrir los valores estéticos de un edificio, que, por deslucido, pasaba inadvertido al común de los transeúntes. Así mismo, no pasó mucho tiempo del inicio de obra para que los medios periodísticos locales y regionales se hicieran eco de la iniciativa y ponderaran las acciones que se documentaron en notas de la prensa escrita, reportajes radiales y programas televisivos. 
La visita de estudiantes universitarios de arquitectura permitió adentrar a los futuros profesionales en sistemas tradicionales de construcción y reparación, como así también en técnicas alternativas, lícitas del punto de vista de la teoría y eficaces desde lo fáctico.

Finalmente, más allá de la cotidiana apropiación que el visitante del cementerio iba realizando del edificio, una iniciativa del equipo de restauración, propiciada por las obras de iluminación del monumento terminó de coronar el proceso de valoración pública del mismo: el Oratorio y la parte patrimonial de la necrópolis fueron incluidos en el itinerario de la Noche de los Museos. Dicho evento, de edición anual y gran poder de convocatoria, propone un recorrido nocturno por sitios de interés cultural diseminados en toda la ciudad. La inesperada oferta de un recorrido nocturno por el cementerio, con sus monumentos funerarios convenientemente iluminados, músicos de cámara acompañando el recorrido guiado y la coronación del mismo en el Oratorio, recuperado, con un concierto de arpa en su interior calaron hondo en los casi dos mil asistentes y cosecharon elogiosas repercusiones en los medios periodísticos.

\section{Conclusión}

De la reflexión teórica inicial y de su correlato en el caso presentado, se puede arribar a una especie de axioma: la postergación en las acciones de conservación y recuperación se debe en muchos casos a la valoración de las obras sobre edificios patrimoniales con las mismas pautas de una obra de construcción regular y a la adopción de sistemas de gestión y contratación que no se adecúan a la realidad particular de la faena. Es virtualmente imposible cotizar una obra sin poder acceder a cada uno de sus rincones, muchas veces a través de medios costosos y no disponibles fácilmente; no se puede evaluar el estado de determinada pieza si no se la retira de su posición; la necesidad de realizar acciones no previstas inicialmente surge una vez comenzados los trabajos por la razonable aparición de patologías ocultas; la toma de decisiones, lejos de parecer una tarea improvisada, debe hacerse casi a diario por que las obras de restauración así lo demandan. Estas notas expuestas y otras tantas, ponen en jaque el sistema de contratación habitual de la obra pública para estos casos específicos y nos enfrentan a la necesidad de crear, fomentar y fortalecer equipos multidisciplinarios con participación del Estado, Universidades, laboratorios de investigación, cooperativas de trabajo, idóneos y profesionales independientes que sean capaces de velar por la conservación e intervenir adecuadamente a la hora de la recuperación, sin el horizonte restrictivo del lucro empresarial como motor principal de una contratación.

El Estado, debe recuperar equipos técnicos con conocimientos e infraestructura para intervenir, conservar y recuperar el patrimonio público y subsidiar la conservación del patrimonio privado de interés comunitario, su rol es indelegable y su ausencia ha propiciado pérdidas que hoy lamentamos.

\section{Referencias}

Aparicio Novoa, G. (2017). Patrimonio Cultural Eclesiástico: Aproximación Conceptual y Normativa Reguladora. Madrid: Universidad Pontificia Comillas.

Constitución Nacional Argentina. (1994). Argentina.

Francisco, P. (2013). Laudato SI': Carta Encíclica Del Sumo Pontífice Francisco : A Los Obispos, a Los Presbíteros Y a Los Diáconos, a Las Personas Consagradas Y a Todos Los Fieles Laicos Sobre El Cuidado De La Casa Común. Ciudad del Vaticano.

Mayordomo Maya, S., \& Hermosilla Pla, J. (2020). Propuesta de un método de evaluación del Patrimonio Cultural y su aplicación en Cortes de Pallás (Valencia). Investigaciones Geográficas - № 73, 216.

Querol, M. A. (2010). Manuel de Gestión del Patrimonio Cultural. Madrid: Ediciones Akal.

Rondina, H., \& Rondina, G. (2019). Tratado de Arquitectura Legal y Derecho Urbano. Santa Fe: Universidad Católica de Santa Fe.

UNESCO. (1972). 17a Convención sobre la Protección del Patrimonio Mundial, Cultural y Natural. París.

Valcárcel Leyva, N. d. (2011). El patrimonio como fenómeno socio-cultural y su contextualización. Obtenido de https://www.redalyc.org/articulo.oa?id=1815

Velasco González, M. (2019). Gestión Turística del Patrimonio Cultural: Enfoques para un Desarrollo Sostenible del Turismo Cultural. Cuadernos de Turismo №23. 